\title{
Polymer fraction of Aloe vera exhibits a protective activity on ethanol-induced gastric lesions
}

\author{
CHUL-HONG PARK ${ }^{1 *}$, DONG-YOON NAM ${ }^{1 *}$, HYEONG-U SON ${ }^{1}$, SI-RIM LEE ${ }^{1}$, HYUN-JIN LEE ${ }^{1}$, \\ JIN-CHUL HEO ${ }^{2}$, TAE-YANG CHA ${ }^{3}$, JIN-HONG BAEK ${ }^{3}$ and SANG-HAN LEE ${ }^{1,2}$ \\ ${ }^{1}$ Department of Food Science and Biotechnology, Graduate School; ${ }^{2}$ Food and Bio-Industry Research Institute, Kyungpook \\ National University, Daegu 702-701; ${ }^{3}$ KimJeongMoon Aloe Company, Ltd., Seongnam 462-729, Republic of Korea
}

Received September 28, 2010; Accepted November 29, 2010

DOI: $10.3892 / \mathrm{ijmm} .2011 .609$

\begin{abstract}
For centuries, Aloe has been used as a herbal plant remedy against skin disorders, diabetes, and for its cardiac stimulatory activity. Here, we examined the gastroprotective effects of an Aloe vera polymer fraction (Avpf; molecular weight cut-off $\geq 50 \mathrm{kDa} ; 150 \mathrm{mg} / \mathrm{kg}$ body weight, p.o.) on an ethanol-induced gastric lesion mouse model. Mice pre-treated with Avpf had significantly fewer gastric lesions than their respective controls. To further examine the potential mechanism underlying this effect, we used reverse transcription-polymerase chain reaction to examine nitric oxide synthase and matrix metalloproteinase (MMP) mRNA expression on tissues from gastric lesions. Our results revealed that the mRNA expressions of inducible nitric oxide synthase (iNOS) and neuronal nitric oxide synthase (nNOS) were each reduced by $\sim 50 \%$ in Avpf-treated mice vs. the controls, whereas, the mRNA expression levels of endothelial nitric oxide synthase remained unchanged. MMP-9, an index for gastric lesions, also alleviated the ethanol-treated gastric ulceration during Avpf treatment. These findings collectively suggest that Avpf significantly protects the gastric mucosa against ethanol-induced gastric damage, at least in part, by decreasing mRNA expression levels of not only iNOS and nNOS, but also MMP-9.
\end{abstract}

Correspondence to: Professor Sang-Han Lee, Department of Food Science and Biotechnology, Kyungpook National University, 1370 SanGyukDong, BukGu, Daegu 702-701, Republic of Korea

E-mail: sang@knu.ac.kr

${ }^{*}$ Contributed equally

Abbreviations: Avpf, polymer fraction of Aloe vera; MMP, matrix metalloproteinase; IL, interleukin; iNOS, inducible nitric oxide synthase; nNOS, neuronal nitric oxide synthase; RT-PCR, reversetranscription polymerase chain reaction

Key words: Aloe vera polymer fraction, nitric oxide synthase, matrix metalloproteinase, ethanol-induction, gastric ulceration

\section{Introduction}

Gastric mucosal damage evokes a pivotal clinical problem worldwide (1). In an effort to expedite the study of acute and chronic gastric damage, scientists have developed several gastric lesion animal models, such as those induced by water immersion restraint (WIRE) stress, ethanol, or indomethacin in rodents (2). These models have previously been used to examine various factors affecting the formation and healing of gastric mucosal lesions (3-5). Ethanol-induced gastric lesions have been used to examine the mechanistic roles of $\mathrm{N}$-acetyl cysteine, acetaminophen and prostaglandins, whereas, the WIRE stress-induced model was used as a model for the investigation of the verapamil, N-ethylmaleimide, and cimetidine mode of action in ulcerogenesis $(2,5,6)$, implying that the two types of gastric lesions have other ulcerogenic pathways. In general, gastric mucosal lesions are derived from disturbances in the gastric barrier that generally guard the mucosa against deep damage by hydrogen ions and other harmful materials formed in the gastric lumen (7). Gastric blood flow is classically regulated by signaling molecules such as prostaglandins, matrix metalloproteinases (MMPs) and cytokines, which play frequent roles in continuing mucosal integrity and have been shown to play a key role in the control of gastric lesions and/or healing (8-11).

On the other hand, Aloe vera Linne is a ubiquitous plant that is easily grown in various climates and is widespread in Asia, Africa, and other tropical areas of the world. The use of Aloe vera is universally being evaluated for a large variety of conditions, such as anti-inflammation and wound healing (12-14). It is now recognized that the Aloe vera extract could promote the healing of burns, cutaneous injuries, edema and can be used in pain reduction $(15,16)$. The plant gel has been shown to protect humans and rodents from gastric ulcerations. The extract also has potential in controlling anti-inflammatory, anti-diabetic, cytoprotective, healing, and mucosal stimulatory activities $(3,16)$. The molecular mechanisms of many activities of these extracts and/or components have not been fully elucidated in vitro and in vivo, but the extracts have been partially shown to have a role in wound healing and inflammation alleviation.

Therefore, in the present study we investigated whether an Aloe vera polymer fraction (Avpf) has potential in alleviating 
gastric mucosal damage in mice, and we further evaluated whether the identified gastroprotective effects exerted via alterations in the mRNA expressions of iNOS and/or nNOS and MMP-9, show that the enzyme expressions are critical biomarkers in ethanol-induced gastric ulceration.

\section{Materials and methods}

Chemicals. TRIzol ${ }^{\circledR}$ reagent was obtained from Invitrogen (Carlsbad, CA). Sodium nitrate was obtained from Janssen Pharmaceutica (Mississauga, Ontario, Canada). Omeprazole, sodium chloride, phosphoric acid, formaldehyde, ethanol, ethidium bromide (EtBr), sulfanilamide, and $\mathrm{N}$-(1-naphthyl) ethylenediamine dihydrochloride (NED) were purchased from Sigma (St. Louis, MO) and QA-Agarose was purchased from QBiogene, Inc. (Irvine, CA). The Avian myeloblastosis virus (AMV) reverse transcriptase (RTase) and Taq-polymerase were purchased from Solgent (Daejeon, Korea). All other chemicals were of analytical grade.

Preparation of a polymer fraction of Aloe vera. Avpf was prepared as follows. The whole leaf $(670 \mathrm{~kg})$ was washed with water and cut into pieces. At the very least, immersion for 3-6 $\mathrm{h}$ was needed to isolate the peeled debris. The resulting waste of pectated materials was up to $335 \mathrm{~kg}(50 \%)$. Prior to centrifugation, the homogenates were crushed. Centrifugation was carried out in order to isolate the dietary fiber fraction [33.5 $\mathrm{kg}(5 \%)]$. A freeze-drying process was used to obtain a lyophilized powder. To prepare the polymer fraction, we carried out the ultrafiltration from the supernatants of the centrifuged fraction. Ultrafiltration from the Aloe fresh gel and the fractionation of its filtrates were carried out using a lab-scale Tami UF system (Tami Industries S.A., France) as previously described (17). The membrane was a commercialgrade external tubular membrane [zirconium dioxide, Tami Valisette module; MW cut-off $(\mathrm{MWCO})=50 \mathrm{kDa}]$ comprised of a $10 \mathrm{~mm}$ diameter, $250 \mathrm{~mm}$ length, $94 \mathrm{~m}^{2}$ area, and was operated at a batch-mode concentration with a final collection of concentrates and filtrates. During the process, the TMP (transmembrane pressure drop), temperature, and speed were $0.2-2.25 \mathrm{bar}, 23^{\circ} \mathrm{C}$, and 240 liters $/ \mathrm{h}$, respectively. By dividing the supernatants to a $50 \mathrm{kDa}$ of MWCO, we finally obtained a retentate fraction $(149.2 \mathrm{~kg}$ ) by discarding the permeate fraction. Concentrates from ultrafiltration were freeze-dried ( 0.5 torr, $24 \mathrm{~h}$ ), and powdered at 80 mesh as the polymer fraction $(0.57 \mathrm{~kg}, 0.085 \%$ yield $)$.

Animals and care. Specific-pathogen-free 6-week-old male $\mathrm{BALB} / \mathrm{c}$ mice, weighing 20 to $\sim 23 \mathrm{~g}$, were obtained from Samtaco Korea (Osan, Korea), and were fed a commercial diet (Samtaco, Osan, Korea) and water ad libitum. The animals were housed under a $12 \mathrm{~h}$ light/dark cycle at a temperature of $22 \pm 1^{\circ} \mathrm{C}$ and a humidity of $55 \pm 5 \%$. Animal care was carried out according to in-house guidelines of the University Animal Care and Use Committee and protocols were in accordance with the guidelines of the International Association for the Study of Pain, Committee for Research and Ethical Issues (Zimmermann, 1983). All animals were allowed to acclimate to the laboratory environment for at least 1 week prior to the experiments.
Induction of gastric ulcerations. The ethanol-induced gastric ulceration mouse model was generated as previously described (18), with a slight modification. Mice were randomly divided into the control (no treatment) group and the ethanol $(8 \mathrm{ml} /$ $\mathrm{kg}$ ), omeprazole $(3 \mathrm{mg} / \mathrm{kg})$, or Avpf $(150 \mathrm{mg} / \mathrm{kg})$ with ethanol treatment groups ( $\mathrm{n}=7$ per group). Omeprazole was used as a positive control, because previous reports have indicated that exogenously administered omeprazole has protective effects against acute gastric ulceration (19). Prior to the injections, food was withdrawn for $24 \mathrm{~h}$, but the mice were allowed free access to water. The mice in the omeprazole treatment group received one per oral (p.o.) administration of $3 \mathrm{mg} / \mathrm{kg}$ omeprazole dissolved in saline, those in the Avpf treatment group ( $n=7$ ) each received one p.o. administration of $150 \mathrm{mg} / \mathrm{kg}$ Avpf, and those in the respective control groups $(n=7)$ each received one p.o. administration of saline. After the administration, mice were returned to their cages for $30 \mathrm{~min}$ to allow for drug absorption, and then received a p.o. injection of $8 \mathrm{ml} / \mathrm{kg}$ ethanol. The mice were not allowed access to food or drink during induction. After $1 \mathrm{~h}$ exposure to ethanol-induction, the mice were euthanized with diethyl ether and their stomachs were removed. Each stomach was cut open along the greater curvature and the gastric mucosa was removed using anatomical scissors. The gastric mucosa was carefully examined for lesions and/or linear breaks (erosions) at the glandular part of the mucosal surface.

Determination of ulcer index. Gastric ulceration was scored as previously reported (18). Briefly, 1 point was scored for small and round hemorrhagic erosions, 2 points when the length of the hemorrhagic erosions was $<1 \mathrm{~mm}, 3$ points when the length was $1 \sim 2 \mathrm{~mm}, 4$ points when the length was $2 \sim 3 \mathrm{~mm}$, and 5 points when the length was $>3 \mathrm{~mm}$. This score was then doubled when the width of the erosion was larger than $1 \mathrm{~mm}$.

Reverse-transcription polymerase chain reaction (RT-PCR) analysis of mRNA expression. Frozen gastric tissue $(\sim 100 \mathrm{mg})$ was homogenized in $1 \mathrm{ml}$ TRIzol ${ }^{\circledR}$ reagent, and total RNA was prepared as described elsewhere $(18,20)$. The total RNA was quantified by a Victor3 spectrophotometer at $260 \mathrm{~nm}$ (Perkin Elmer, Wellesley, MA) and the RNA quality was examined by $1 \%$ formaldehyde-agarose gel electrophoresis and $\mathrm{EtBr}$ staining. The RNA samples were then stored at $-80^{\circ} \mathrm{C}$ until use. Reverse-transcription was performed using the AMV-RTase and the PCR was performed using the Taq-polymerase along with specific primer sets. These primers were designed using the Primer3 software (Whitehead Institute, MIT Center for Genome Research, Cambridge, MA) to analyze sequences deposited in the NCBI GenBank database. The primers were synthesized by Bioneer Co. (Daejeon, Korea) as follows: epidermal growth factor (EGF), forward (F): 5'-ACT CGG AAG CAG CTA TCA AAC C-3' and backward (R): 5'-CCT CTA TTT CCT GGG GTC CTC T-3', 337 bp; $\beta$-cellulin (BTC), F: 5'-CTG GTG GTC TGC TTG ATA GTG G-3' and R: 5'-CCT GAG ACA TGT CCT GTC CAT C-3', 256 bp; cyclooxygenase (COX)-1, F: 5'-ATC CCA TCT GTT CCC CAG AGT A-3' and R: 5'-ACG AAA ACC CAC ATC AAG GAC T-3', 267 bp; COX-2, F: 5'-TCG ATG TCA TGG AAC TGT ACC C-3' and R: 5'-TAG GCT GTG GAT CTT GCA 
CAT T-3', 270 bp; iNOS, F: 5'-AAC CCA AGG TCT ACG TTC AGG A-3' and R: 5'-TTA CTC AGT GCC AGA AGC TGG A-3', 335 bp; nNOS, F: 5'-AAG AAC AAG GGC GTC TTC AGA G-3' and R: 5'-TAA GGC GGT GGT CAC TTC ATA-3', 328 bp; MMP-2, F: 5'-TGT TCT TCG CAG GGA ATG AGT A-3' and R: 5'-ACT TTG GTT CTC CAG CTT CAG G-3', 335 bp; MMP-3, F: 5'-TTT CCC AGG AAG ATA GCT GAG G-3' and R: 5'-CTG GTG TCA TCC ATA GCT CCT G-3', 302 bp; MMP-9, F: 5'-CCC AGG AGT CTG GAT AAG TTG G-3' and R: 5'-AGG AGG TCG TAG GTC ACG TAG C-3', 335 bp; mucin 5AC core protein (MUC5AC), F: 5'-CCA TGT GTA TTC CTC TCC CAC A-3' and R: 5'-CTG ACC CAG ATC CTC CAT CTC T-3', 304 bp; and 18's RNA, F: 5'-ATG TGG TGT TGA GGA AAG CAG A-3' and R: 5'-TCT TGG ATA CAC CCA CAG TTC G-3', 327 bp. Briefly, first-strand of cDNA was reverse-transcribed from $500 \mathrm{ng}$ of total RNA at $45^{\circ} \mathrm{C}$ for $60 \mathrm{~min}$, the samples were denatured for 5 min at $95^{\circ} \mathrm{C}$, and PCR amplification was performed with 32 cycles (EGF, BTC, COX-1, COX-2, MMP-2, MMP-3, MMP-9, and MUC5AC) or 34 cycles (iNOS, eNOS, and nNOS), or 20 cycles (18s RNA) of $30 \mathrm{sec}$ at $95^{\circ} \mathrm{C}, 30 \mathrm{sec}$ at $56^{\circ} \mathrm{C}$, and $45 \mathrm{sec}$ at $72^{\circ} \mathrm{C}$. Following amplification, $20 \mu \mathrm{l}$ of each product was resolved by $1 \%$ agarose gel electrophoresis and visualized by EtBr staining. The location of the predicted product was confirmed by comparison to a $1 \mathrm{~kb}$ DNA ladder (Solgent, Daejeon, Korea). For semi-quantitative analysis, the relative amounts of cDNA in each matched set were normalized, with regard to the 18s RNA expression, using the Molecular Imager Gel Doc XR System and the Quantity One 1-D analysis software (Bio-Rad, Philadelphia, PA).

Mucus layer staining by periodic acid-Schiff (PAS). The mucus layer was identified by PAS staining as described elsewhere (21). Briefly, after de-paraffinization and rehydration, tissue sections were oxidized in $1 \%(\mathrm{v} / \mathrm{v})$ periodic acid for $5 \mathrm{~min}$. They were then rinsed in distilled water and stained with Schiff's reagent for $15 \mathrm{~min}$. After another washing with distilled water, they were counter-stained with Mayer's hematoxylin and rinsed in running tap water. Finally, they were dehydrated, cleared, and mounted. Sections were viewed under a microscope (Axiovert 200, Carl Zeiss, Germany) and the thickness of the mucus-secreting layer was assessed under an image analyzer (x100).

Immunohistochemical expression of MMP-9. Immunohistochemical analysis was carried out as previously described (20). In brief, tissues were embedded in paraffin, cut into 4-6 mm sections, and set overnight on a slide warmer at $37^{\circ} \mathrm{C}$. The paraffin was removed with xylene and the tissues sections were exposed to serial dilutions of 70-100\% ethanol for $60 \mathrm{~min}$. After washing, the tissues were processed for immunohistochemical analysis. Tissue sections were treated with $10 \%$ normal goat serum for $1 \mathrm{~h}$ at room temperature to block non-specific binding. Slides were subsequently incubated overnight at $4^{\circ} \mathrm{C}$ with rabbit anti-MMP-9 antibody (Santa Cruz Biotechnology; 1:200).

Statistical analyses. Data are presented as means \pm standard deviations (SD). The one-way analysis of variance (ANOVA) and the Dunnett's test were used for statistical analyses (22). $\mathrm{P}$-values of $<0.05$ were considered statistically significant.
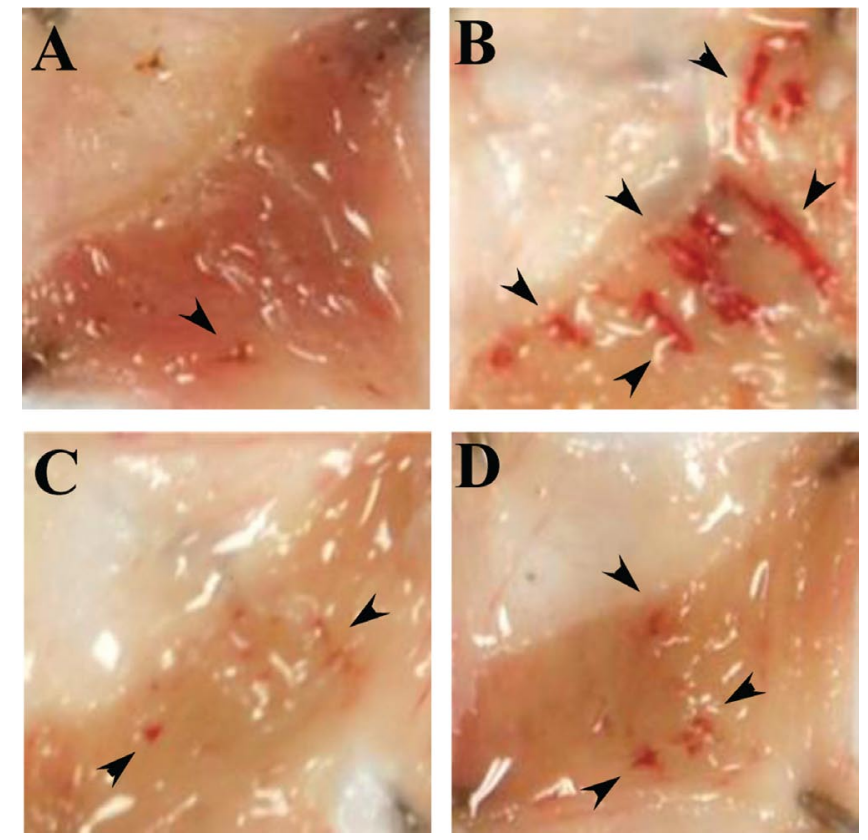

Figure 1. Effects of Avpf in an ethanol-induced mouse gastric ulceration model. Mice were randomly divided into control (A), ethanol (B; $8 \mathrm{ml} / \mathrm{kg}$ ), polymer $(\mathrm{C} ; 150 \mathrm{ml} / \mathrm{kg})$, or omeprazole $(\mathrm{D} ; 3 \mathrm{mg} / \mathrm{kg})$, with ethanol treatment $(8 \mathrm{ml} / \mathrm{kg}$ ) ( $\mathrm{n}=7$ mice per group). After the p.o. injections, mice were returned to their cages for $30 \mathrm{~min}$ to allow drug absorption. The mice were not allowed access to food or drink during induction. Mice were euthanized and their stomachs were examined for gastric lesions, which were visualized as either punctate or linear forms.

\section{Results}

Effect of Avpf on ethanol-induced gastric ulceration. Half an hour prior to initiation of ethanol induction, the negative control mice received a p.o. injection of saline, whereas positive control mice received a p.o. injection of omeprazole at a concentration of $3 \mathrm{mg} / \mathrm{kg}$. Experimental mice groups received a p.o. injection of Avpf $(150 \mathrm{mg} / \mathrm{kg})$. After $1 \mathrm{~h}$ exposure to ethanol induction $(8 \mathrm{ml} / \mathrm{kg})$, all mice were euthanized and their stomachs were examined for gastric ulceration, as punctate or linear form. In samples from p.o.-injected ethanolinduced groups, we observed numerous lesions (Fig. 1B), most often 1 to $\sim 2 \mathrm{~mm}$ in size. In contrast, the omeprazole-treated mice group showed very few lesions as shown in Fig. 1D, while the control group showed no large size gastric lesions (Fig. 1A). Only small size gastric lesions could be detected in the positive control group (Fig. 1D), which is not significant when compared to the ethanol-induced group. In Fig. 1C, Avpf-treated mice showed small size and minor but numerous lesions. By scoring mucosal lesions with a slight modification (23), we compared the ulcer index as shown in Fig. 2. The ulcer index of the ethanol-treated control was 29.5 \pm 6.9 , whereas that of the omeprazole-treated group was 12.0 \pm 5.6 . The polymer treatment dramatically reduced the ulcer index to $6.2 \pm 3.3$ points, which was equal to $89.3 \%$ inhibition level). Collectively, these findings indicate that Avpf protects against ethanol-induced gastric lesions in mice.

Histological morphology. By staining to assess whether the stomach tissues were damaged or not, we confirmed that the 


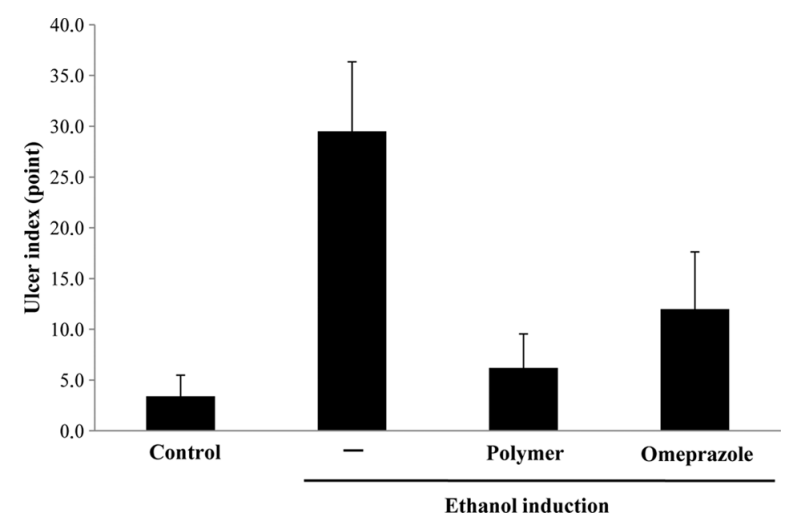

Figure 2. Effects of Avpf on ethanol-induced ulceration development of gastric mucosal lesions. Gastric ulceration was scored as previously reported (18). Data are the mean $\pm \mathrm{SD}$ ( $\mathrm{n}=7$ animals per group). $\mathrm{P}<0.05$ compared with the p.o.-injected control group. The results were analyzed by one-way ANOVA followed by the Dunnett's test.

ethanol-administered group displayed more potent staining than the control group. Photographs of stomachs of the control group (no treatment), and ethanol $(8 \mathrm{ml} / \mathrm{kg})$, polymer fraction (each $150 \mathrm{ml} / \mathrm{kg}$ ) or omeprazole $(3 \mathrm{mg} / \mathrm{kg}$ ) with the ethanol treatment groups of mice after PAS staining are shown in Fig. 3. In Fig. 3B, the phenomenon indicates that an inflammatory lesion was smeared by PAS and it turned red. On the other hand, the Avpf-treated group (Fig. 3C) had a significantly decreased number of gastric pits and inflammatory infiltration than the ethanol alone group (Fig. 3B), indicating that the active components of Avpf ameliorate the inflammatory reac- tion with gastric lesions. Using PAS staining we concluded that Avpf has potential in mitigating the quantity of the ethanolinduced gastric lesions on stomach tissues in mice.

mRNA expression profiles of inflammatory markers. Next, we investigated the molecular mechanisms that are associated with the ethanol-induced gastric lesions in mice. We first carried out RT-PCR of some molecular markers regarding gastric inflammation, in order to compare the mRNA expressions with or without Avpf in the gastric lesions. As shown in Fig. 4, the mRNA expressions of the inflammation markers, COX-1, COX-2, and BTC during ethanol-induced gastric lesions were not significantly altered. When EGF expression was evaluated at the mRNA level, a slight decrease in its expression level was observed in the Avpf-treated mice. Expression of MUC5AC, an anti-inflammation ulcer mediator, decreased when the gastric tissues were exposed to ethanol administration and recovered with Avpf treatment.

Expression levels of NOSs mRNA. Interestingly, iNOS and nNOS mRNA expression levels were of the same pattern as shown in Fig. 5A and B. In particular, nNOS is constitutive; therefore, it is well known that the expression level does not severely change in the normal state of the human body during homeostasis. However, in this case, the mRNA expression level profile of nNOS was profoundly altered (Fig. 5C and D).

Levels of MMP expressions. We further investigated whether the MMPs are associated with gastroprotection by Avpf. Of 18 kinds of MMPs, MMP-9, as shown in Fig. 6C and D, had
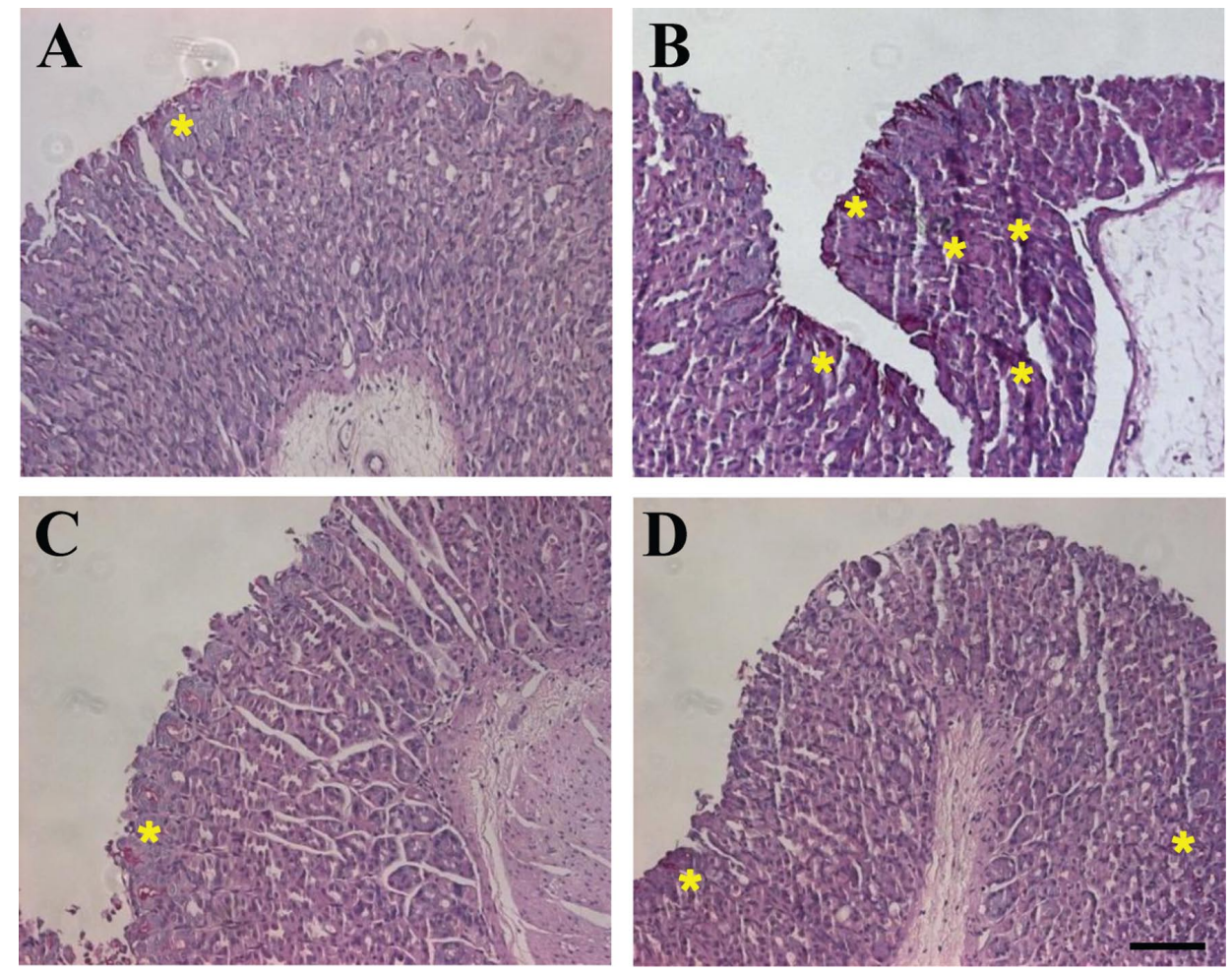

Figure 3. Immunopathological analysis of ethanol-induced gastric mucosal lesions. After de-paraffinization and rehydration, tissue sections were oxidized in $1 \%(\mathrm{v} / \mathrm{v})$ periodic acid for $5 \mathrm{~min}$, rinsed in distilled water and stained with Schiff's reagent for 15 min. After another washing with distilled water, they were counterstained with Mayer's hematoxylin and rinsed in running tap water. Finally, they were dehydrated, cleared, and mounted. Sections of the control group (A), ethanol-treated group alone (B), ethanol-treated group with polymer fraction (C), or the omeprazole-treated group (D) were viewed under a microscope (Axiovert 200, Carl Zeiss, Germany). Asterisks denote gastric lesions. Scalebar, $100 \mu \mathrm{m}$. 


\section{Ethanol induction}

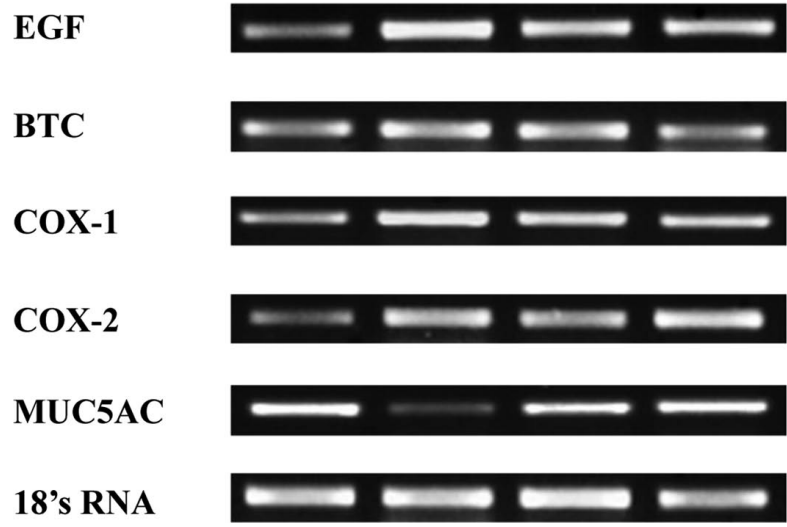

Figure 4. Comparison of mRNA expressions in ethanol-induced ulcerations by RT-PCR. The PCR conditions are shown in Materials and methods. The data represent a classical observation of three independent determinations.

a 6-fold higher increase in its expression level compared to the expression of MMP-2, or -3 (Fig. 6A or B). The increase was drastically decreased by the Avpf treatment, resulting in a drop to baseline levels similar to the control. The expressions of the other MMPs did not change more than 2-fold compared to control (data not shown). By immunohistochemical analysis, we assessed that the tissue expression levels were correlated to the RT-PCR data. As shown in Fig. 7, immunohistochemical analyses revealed that a marked reduction in the number of MMP-9-positive cells in tissues from the ethanol-treated group (asterisks in Fig. 7B) could be recovered by Avpf treatment (Fig. 7C). The expression of MMP-9 was also markedly reduced in tissues of the omeprazole-treated group (asterisks in Fig. 7D) as compared to those of the ethanol-treated group (asterisks in Fig. 7B), but the expression intensity was not greater than that of cells of Avpf-treated animals.

\section{Discussion}

We have shown for the first time that a polymer fraction (>50 kDa of MWCO) of Aloe vera (Avpf) decreased the ethanol-induced gastric mucosal lesions in mice by lowering the mRNA expression levels of not only iNOS and nNOS, but also of MMP-9.

First, we examined whether the gastroprotective effects of Avpf involve the suppression of nitric oxide (NO) levels via a decreased mRNA expression of iNOS. Previous studies have demonstrated that WIRE stress-induced gastric mucosal lesions are associated with increased gastric acid production, accelerated gastric peristalsis, microcirculation disturbances in the gastric mucosa, decreased prostaglandin levels, low turnover of gastric mucous cells, and NO-mediated changes in the homeostatic functions of the gastric mucosa $(8,18)$. The NO-mediated regulation plays a key role in gastric mucosal protection against damage induced by ethanol, stress, drugs, and/or endotoxins. The mechanism of this NO-mediated protection is conducted through the NOS activity within the gastric tissues (24).

In the present study, we hypothesized that the Avpf-treated mice with ethanol-administration would have lower serum and gastric tissue NO contents compared to the ethanol alone group. Similar results were obtained from the omeprazoletreated mice, which were used as a positive control (25). To test one possible mechanism underlying these gastroprotective effects, we examined the mRNA expression levels of various NOS. The present results revealed that the gastric mucosal mRNA expressions of iNOS and nNOS were significantly lower in Avpf- and omeprazole-treated mice compared to the control mice, whereas no such differences were observed in eNOS mRNA expression levels (data not shown). These findings collectively suggest that the protective expression levels of NOS against ethanol-induced gastric damage in mice may originate, at least in part, from the suppression of NO signaling exerted through decreases in the mRNA expression levels of iNOS and/or nNOS by the Avpf treatment.
A
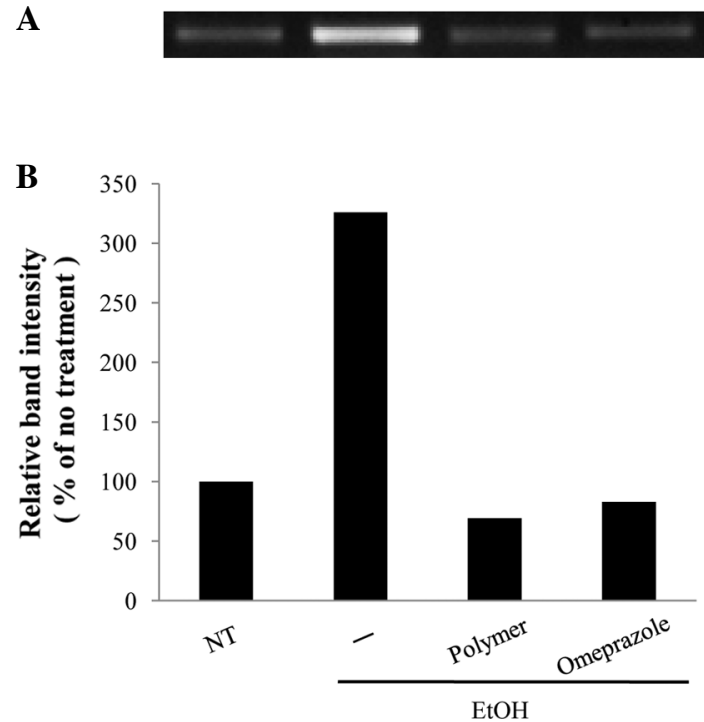

C

D

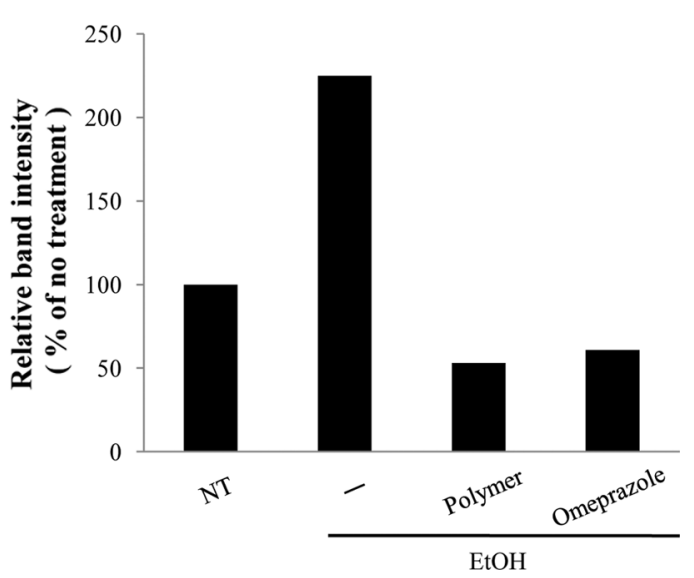

Figure 5. Comparison of the relative intensity of mRNA expressions of iNOS (A and B) and nNOS (C and D) by Avpf. NT, no treatment. 


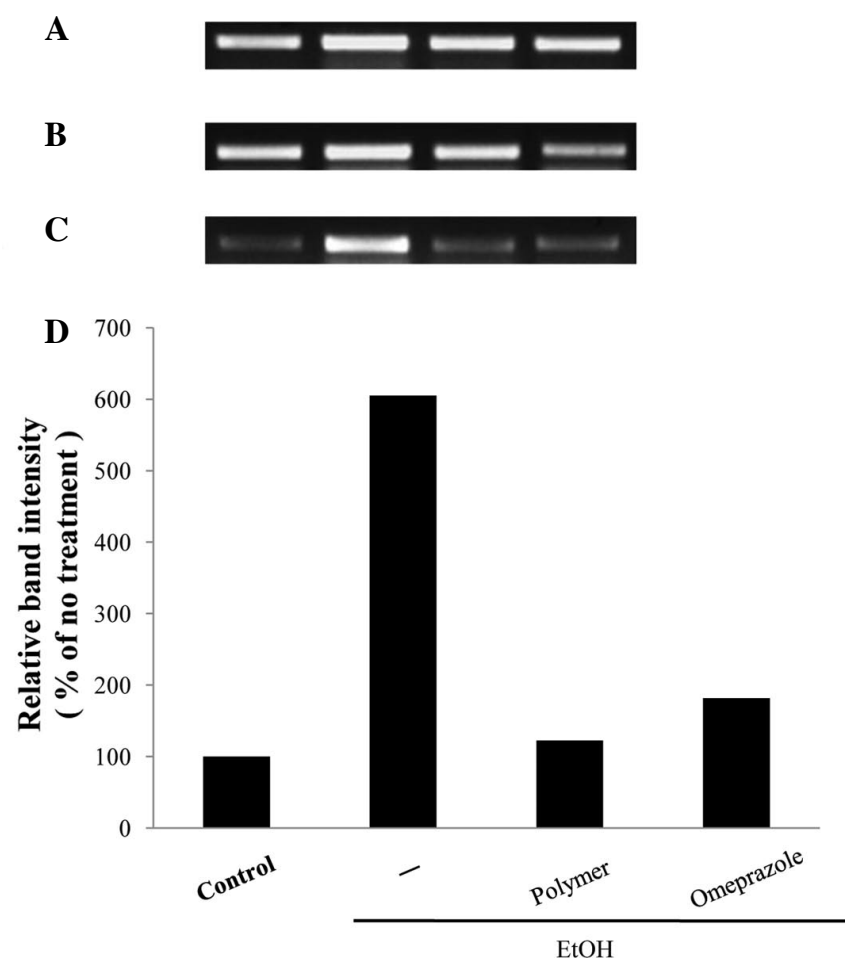

Figure 6. Relative intensity of mRNA expressions of MMP-2 (A), MMP-3 (B), MMP-9 (C and D) by Avpf.

Previous studies have indicated the importance of cNOS in the maintainance of an undamaged gastric mucosa (26). Decreased cNOS activity has been correlated with gastric erosion, while increased cNOS mRNA expression, activity and immunoreactivity have been seen in the healing gastric mucosa, particularly in newly formed vessels and neurons (27). Consistent with the notion that cNOS is a pivotal factor in gastric tissue repair, cigarette smoking-induced reductions in mucosal NOS activity have been associated with decreased gastric blood flow and suppression of angiogenesis at ulcer margins (28). However, we did not observe altered eNOS expressions in Avpf- or omeprazole-treated mice exposed to ethanol treatment. Interestingly, we found dramatic changes in the mRNA expression levels of iNOS and nNOS, suggesting that these isoforms may be involved in the mechanism(s) of Avpf-induced gastroprotection.

Large amounts of iNOS-produced NO have been implicated in gastric damage during inflammatory reactions (29), and high iNOS expression and activity have been associated with severe gastric inflammation in ulcerative mucosal tissues (30). Studies have shown that iNOS is usually induced under oxidative conditions, as high levels of NO can bind with the superoxide anion $\left(\mathrm{O}_{2}^{-}\right)$, thus leading to the formation of peroxynitrite $\left(\mathrm{ONOO}^{-}\right)$, as well as to protein tyrosine nitration, hydroxyl radical formation, cellular toxicity, and direct tissue injury $(30,31)$. In the present study, we observed high-level iNOS and nNOS mRNA expressions in the gastric mucosal lesions of ethanol-treated mice, but profoundly lowered levels in the Avpf-treated mice, suggesting that the Avpf can inhibit NO production by decreasing iNOS and nNOS expressions in the gastric mucosal lesions of ethanol-treated mice. This may prevent the abundant release of damaging NO, resulting in gastroprotection.

It is known that iNOS expression increases when gastric inflammation occurs which promotes generation of $\mathrm{NO}$ or ROS. The Avpf can suppress the expression levels that can
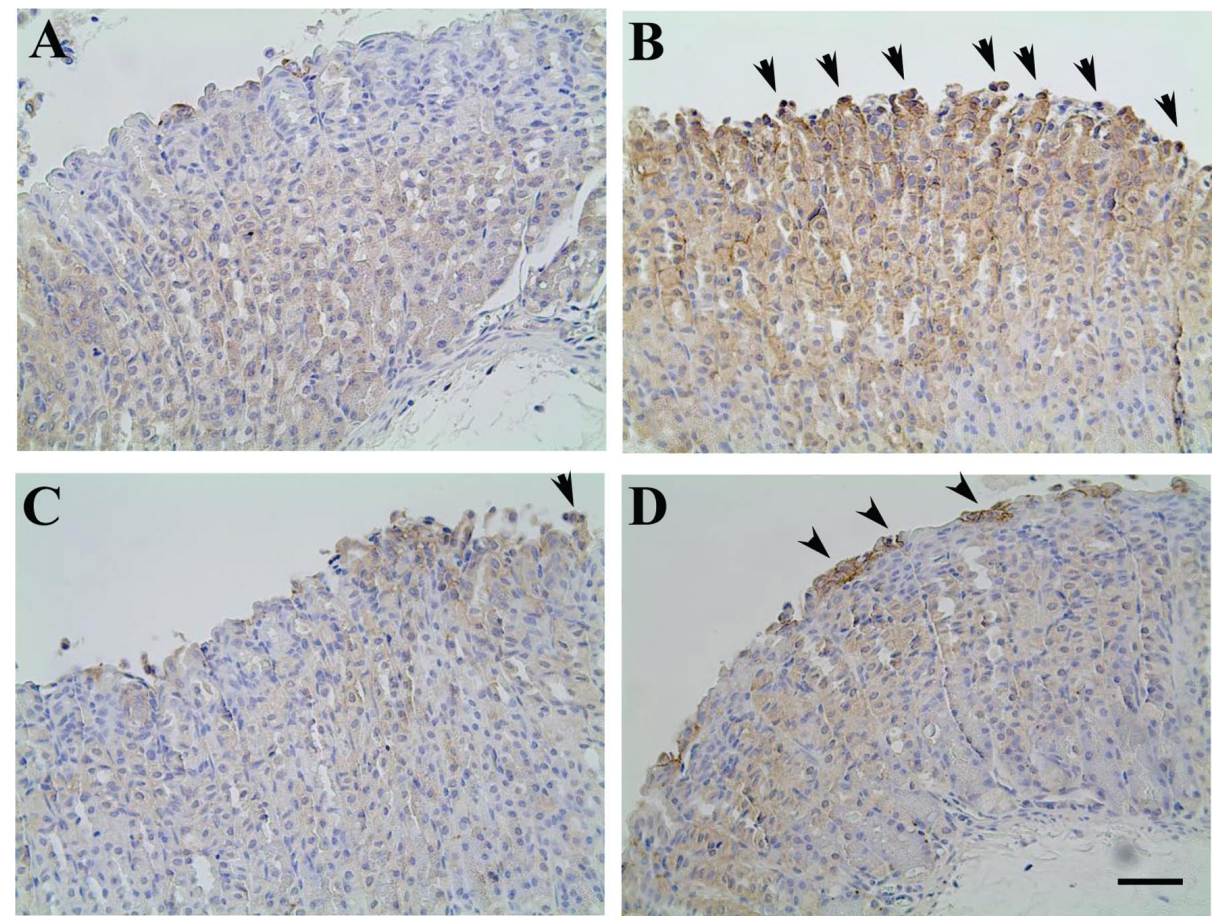

Figure 7. Immunohistochemical analysis of MMP-9 protein expression on ethanol-induced gastric mucosal lesions by Avpf. Sections of control group (A), ethanol-treated group alone (B), ethanol-treated group with polymer fraction (C), or omeprazole-treated group (D) were immunostained by MMP-9 antibody and visualized by a secondary antibody. Dense violet blots denote MMP-9 positive cells that are secreted or bound to the MMP-9 proteins in the cell membranes or into the cells. Scalebar, $100 \mu \mathrm{m}$. 
influence the extent of iNOS inhibition. Using ethanol-induced gastric ulcers, the increased expression of nNOS was demonstrated in the present study. The Avpf also triggers nNOS expression levels that were determined by RT-PCR.

On the other hand, MMPs are a family of proteinases that are associated with tissue remodeling and wound healing $(32,33)$. It is for this reason, that the alcohol-induced gastric ulceration is dependent on the expression pattern of MMPs (34). In the present study, we did not detect any significant differences between MMP-2 and -3 (Fig. 6A and B). However, MMP-9 mRNA expression levels were approximately 6-fold higher than those of the control (Fig. 6C and D). Clearly, the Avpf-induced MMP-9 expression levels were significantly reduced and reached the same levels of the control, similarly to those of the omeprazole-treated group (Fig. 6C, lanes 3 and 4, and Fig. 6D, columns 3 and 4). Evaluation of the MMP-9 expression pattern by immunohistochemistry using an MMP-9 antibody, revealed a similar enzyme expression pattern to that detected by the band intensity of the RT-PCR (Fig. 6C and D), by the pattern of gastric lesions (Fig. $1 \mathrm{C}$ and D), by assessment of the gastric ulcer index (Fig. 2, columns 3 and 4), and by the immunostaining profile (Fig. 3C and D).

We have shown for the first time that exogenously administered Avpf protects against the development of ethanol-induced gastric mucosal lesions in mice, and that Aloe's anti-ulcer effect may be due, at least partially, to the reduced mRNA expressions of iNOS and nNOS as well as to those of MMP-9. Although future studies will be focused on the isolation of pure Aloe compound(s) for their protective effects, these novel findings present a new era in the nutraceutical application of Aloe. The present investigation has key impact suggesting that this herbal plant and/or related fraction could be developed for future application in ulcer prevention and therapy.

\section{Acknowledgements}

We appreciate Ms. Eun-Young Kwon for her technical assistance. C.-H. P., J.-H. B. and S.-H. L. designed the research; C.-H. P., J.-C. H. and T.-Y. C. performed the research; J.-H. B. and S.-H. L. analyzed the data; and C.-H. P. and S.-H. L. wrote the manuscript.

\section{References}

1. Mózsik G, Dömötör A, Rumi G and Szekeres G: Gastrointestinal cytoprotection: from basic science to clinical perspectives. Inflammopharmacology 15: 49-60, 2007.

2. Cho $\mathrm{CH}$ and Ogle $\mathrm{CW}$ : The pharmacological differences and similarities between stress- and ethanol-induced gastric mucosal damage. Life Sci 51: 1833-1842, 1992.

3. Gyires K: Gastric mucosal protection: from prostaglandins to gene-therapy. Curr Med Chem 12: 203-215, 2005.

4. Halter F, Tarnawski AS, Schmassmann A and Peskar BM: Cyclooxygenase 2-implications on maintenance of gastric mucosal integrity and ulcer healing: controversial issues and perspectives. Gut 49: 443-453, 2001.

5. Evangelista S: Role of sensory neurons in restitution and healing of gastric ulcers. Curr Pharm Des 12: 2977-2984, 2006.

6. Maity P, Biswas K, Roy S, Banerjee RK and Bandyopadhyay U: Smoking and the pathogenesis of gastroduodenal ulcer: recent mechanistic update. Mol Cell Biochem 253: 329-338, 2003.

7. Krishnan P: The scientific study of herbal wound healing therapies: current state of play. Curr Anaesth Crit Care 17: 21-27, 2006.

8. Ham M and Kaunitz JD: Gastroduodenal mucosal defense. Curr Opin Gastroenterol 24: 665-673, 2008.
9. Szabo S, Vincze A, Sandor Z, Jadus M, Gombos Z, Pedram A, Levin E, Hagar J and Iaquinto G: Vascular approach to gastroduodenal ulceration: new studies with endothelins and VEGF. Dig Dis Sci 43 (Suppl 9): 40S-45S, 1998.

10. Konturek SJ, Konturek PC and Brzozowski T: Melatonin in gastroprotection against stress-induced acute gastric lesions and in healing of chronic gastric ulcers. J Physiol Pharmacol 57 (Suppl 5): 51S-66S, 2006.

11. Hatazawa R, Ohno R, Tanigami M, Tanaka A and Takeuchi K: Roles of endogenous prostaglandins and cyclooxygenase isozyme in healing of indomethacin-induced small intestinal lesions in rats. J Pharmacol Exp Ther 318: 691-699, 2006.

12. Eamlamnam K, Patumraj S, Visedopas N and Thong-Ngam D: Effects of Aloe vera and sucralfate on gastric microcirculatory changes, cytokine levels and gastric ulcer healing in rats. World J Gastroenterol 12: 2034-2039, 2006.

13. Yusuf S, Agunu A and Diana M: The effect of Aloe vera A. Berger (Liliaceae) on gastric acid secretion and acute gastric mucosal injury in rats. J Ethnopharmacol 93: 33-37, 2004.

14. Cosmetic Ingredient Review Expert Panel: Final report on the safety assessment of Aloe andongensis extract, Aloe andongensis leaf juice, Aloe arborescens leaf extract, Aloe arborescens leaf juice, Aloe arborescens leaf protoplasts, Aloe barbadensis flower extract, Aloe barbadensis leaf, Aloe barbadensis leaf extract, Aloe barbadensis leaf juice, Aloe barbadensis leaf polysaccharides, Aloe barbadensis leaf water, Aloe ferox leaf extract, Aloe ferox leaf juice, and Aloe ferox leaf juice extract. Int J Toxicol 26 (S2): 1S-50S, 2007.

15. Chithra P and Sajithlal GB and Chandrakasan G: Influence of Aloe vera on the healing of dermal wounds in diabetic rats. J Ethnopharmacol 59: 195-201, 1998.

16. Davis RH, Donato JJ, Hartman GM and Haas RC: Antiinflammatory and wound healing activity of a growth substance in Aloe vera. J Am Podiatr Med Assoc 84: 77-81, 1994.

17. Baek J-H, Cha T-Y, Heo JC, Lee S-H and Lee S-Y: In vitro and in vivo physiological characteristics of dietary fiber from by-products of Aloe vera gel processing. Food Eng Prog 14: $173-182,2010$

18. An SM, Park CH, Heo JC, Park JY, Woo SW, Seo JH, Lee MS, Cho KH, Shin HM and Lee S-H: Gastrodia elata Blume protects against stress-induced gastric mucosal lesions in mice. Int J Mol Med 20: 209-215, 2007.

19. Julapalli VR and Graham DY: Appropriate use of intravenous proton pump inhibitors in the management of bleeding peptic ulcer. Dig Dis Sci 50: 1185-1193, 2005.

20. Heo JC, Rho JR, Kim TH, Kim SY and Lee SH: An aqueous extract of green tea Camellia sinensis increases expression of Th1 cell-specific anti-asthmatic markers. Int J Mol Med 22: 763-767, 2008.

21. Banerjee D, Bauri AK, Guha RK, Bandyopadhyay SK and Chattopadhyay S: Healing properties of malabaricone B and malabaricone $\mathrm{C}$, against indomethacin-induced gastric ulceration and mechanism of action. Eur J Pharmacol 578: 300-312, 2008.

22. Heo JC, Park JY, Woo SU, Rho JR, Lee HJ, Kim SU, Kho YH and Lee S-H: Dykellic acid inhibits cell migration and tube formation by RhoA-GTP expression. Biol Pharm Bull 29: 2256-2259, 2006.

23. Nie SN, Qian XM, Wu XH, Yang SY, Tang WJ, Xu BH, Huang F, Lin X, Sun DY, Sun HC and Li ZS: Role of TFF in healing of stress-induced gastric lesions. World J Gastroenterol 9: 1772-1776, 2003.

24. Lundberg JO, Weitzberg E and Gladwin MT: The nitrate-nitritenitric oxide pathway in physiology and therapeutics. Nat Rev Drug Discov 7: 156-167, 2008.

25. DeVault KR and Talley NJ: Insights into the future of gastric acid suppression. Nat Rev Gastroenterol Hepatol 6: 524-532, 2009.

26. Suvitayavat W, Bunyapraphatsara N, Thirawarapan SS and Watanabe K: Gastric acid secretion inbititory and gastric lesion protective effects of Aloe preparation. Thai J Phytopharm 4: 1-11, 1997.

27. Brzozowski T, Konturek PC, Konturek SJ, Pajdo R, Drozdowicz D, Kwiecien S and Hahn EG: Acceleration of ulcer healing by cholecystokinin (CCK): role of CCK-A receptors, somatostatin, nitric oxide and sensory nerves. Regul Pept 82: 19-33, 1999.

28. Ma L, Chow JY and Cho CH: Cigarette smoking delays ulcer healing: role of constitutive nitric oxide synthase in rat stomach. Am J Physiol 276: 238-248, 1999.

29. Barrachina MD, Panes J and Esplugues JV: Role of nitric oxide in gastrointestinal inflammatory and ulcerative diseases: perspective for drugs development. Curr Pharm Des 7: 31-48, 2001. 
30. Kankuri E, Vaali K, Knowles RG, Lahde M, Korpela R, Vapaatalo $\mathrm{H}$ and Moilanen E: Suppression of acute experimental colitis by a highly selective inducible nitric-oxide synthase inhibitor, N-[3-(aminomethyl)benzyl]acetamidine. J Pharmacol Exp Ther 298: 1128-1132, 2001.

31. Ding HL, Zhu HF, Dong JW, Zhu WZ, Yang WW, Yang HT and Zhou ZN: Inducible nitric oxide synthase contributes to intermittent hypoxia against ischemia/reperfusion injury. Acta Pharmacol Sin 26: 315-322, 2005.

32. Shahin M, Konturek JW, Pohle T, Schuppan D, Herbst H and Domschke W: Remodeling of extracellular matrix in gastric ulceration. Microsc Res Technol 53: 396-408, 2001.
33. Swarnakar S, Ganguly K, Kundu P, Banerjee A, Maity P and Sharma AV: Curcumin regulates expression and activity of matrix metalloproteinases 9 and 2 during prevention and healing of indomethacin-induced gastric ulcer. J Biol Chem 280: 9409-9415, 2005.

34. Pradeepkumar SL, Kundu P, Ganguly K, Mishra A and Swarnakar S: Novel role of famotidine in downregulation of matrix metalloproteinase-9 during protection of ethanol-induced acute gastric ulcer. Free Radic Biol Med 43: 289-299, 2007. 